\title{
Manejo de Paspalum dilatatum Poir. biótipo Virasoro. 2. Produção de sementes
}

\author{
Simone Meredith Scheffer-Basso ${ }^{1}$, Vanessa Trentini' ${ }^{2}$, Karinne Baréa $^{3}$ \\ 1 Universidade de Passo Fundo, Campus I, Bairro São José, Passo Fundo, Rio Grande do Sul, Cep: 99001-970. Bolsista CNPq. \\ 2 Bióloga. \\ ${ }^{3}$ Bióloga, MSc.
}

RESUMO - Objetivou-se avaliar o efeito da altura (10 e $20 \mathrm{~cm}$ ) e do intervalo de cortes (30 e 45 dias) na produção de sementes de capim-melador (Paspalum dilatatum Poir.) em condições de campo. As plantas foram cortadas nove e seis vezes, respectivamente, nos intervalos de corte de 30 e 45 dias, no período de setembro de 2003 a junho de 2004 . Foram feitas duas colheitas de sementes, em 19/11/2004 (44,4 g sementes/linha) e 17/12/2004 (15,8 g sementes/linha). O manejo influenciou a produção e a germinação das sementes, que foram maiores nos cortes realizados a $10 \mathrm{~cm}$ de altura (47,9 g sementes/linha) e a intervalos de 45 dias (50,3 g semente/planta) em comparação aos cortes a $20 \mathrm{~cm}$ (41 g sementes/linha) e a $30 \mathrm{~cm}$ de altura (38,7 g semente/linha). O número de panículas foi o principal componente da produção. Na primeira colheita, a germinação de sementes foi maior nos intervalos de 30 dias (12,4\% vs 6,6\%). Na segunda colheita, a germinação foi maior nas alturas de $10 \mathrm{~cm}$ (5,6\%), em comparação à de $20 \mathrm{~cm}$ (3,3\%), e de $30 \mathrm{~cm}(5,3 \%)$, em relação à de $45 \mathrm{~cm}$ (3,6\%). As principais limitações na produção de sementes do capim-melador foi o florescimento contínuo e o curto intervalo do florescimento pleno ao início da abscisão das espiguetas, o que causou a mistura de sementes com diferentes graus de maturação nos lotes selecionados.

Palavras-chave: cortes, fenologia, reprodução

\section{Management of Paspalum dilatatum Por. biotype Virasoro. 2. Seed production}

\begin{abstract}
This work aimed to evaluate the effect of the cutting height $(10 \mathrm{~cm}$ and $20 \mathrm{~cm}$ ) and cutting interval (30 days and 45 days) on the seed production of dallisgrass cultivated under field conditions. Plants were cut between September/ 2003 and June/2004, nine and six times, for the $30 \mathrm{~d}$ and $45 \mathrm{~d}$ cutting interval, respectively. Seed harvests were performed on 19/11/2004 (44 $\mathrm{g}$ of seeds/row) and 17/12/2004 (15.8 g of seeds/row). There was significant effect of the cutting management in the seed production and germination, with greater seed yield in the $10 \mathrm{~cm}$ cutting height (47.9 g of seeds/row) compared to $20 \mathrm{~cm}$ cutting height (41 g of seeds/row), and to $45 \mathrm{~d}$ cutting interval ( $50.3 \mathrm{~g}$ of seeds/row) compared to $30 \mathrm{~d}$ cutting interval (38.7 $\mathrm{g}$ of seeds/row). Panicle number was the principal seed production component. For the $1^{\text {st }}$ harvest, the seed germination was superior at the $30 \mathrm{~d}$ cutting interval (12.4\%) compared to $45 \mathrm{~d}$ cutting interval (6.6\%); at the $2^{\text {nd }}$ harvest, seed germination was higher in the $10 \mathrm{~cm}$ cutting height (5.6\%) compared to $20 \mathrm{~cm}$ cutting height (3.3\%) and to $30 \mathrm{~d}$ cutting interval (5.3\%) compared to $45 \mathrm{~d}$ cutting interval (3.6\%). The major limitation for dallisgrass seed production was its continuous flowering and the short interval between the full flowering and the spikelet abscission initiation, which caused different maturation degrees in the lot of harvested seed.
\end{abstract}

Key Words: cutting, phenology, reproduction

\section{Introdução}

A persistência de espécies nativas forrageiras de elevado valor nutritivo é extremamente desejável e particularmente importante para as pastagens naturais do Sul do Brasil, pois constituem principal fonte alimentar dos rebanhos. Essa persistência pode ser obtida tanto pela sobrevivência dos indivíduos como pelo surgimento de novas plantas, por meio da ressemeadura natural. Assim, a quantidade e as características das sementes geradas a cada temporada são determinantes para a manutenção dessas comunidades e dependem das intervenções sobre as plantasmães durante seu crescimento, ou seja, do momento e da intensidade com que são utilizadas pelos animais (Jonhston et al., 2003). O pastejo pode ser estrategicamente aplicado à produção de sementes, pois interfere na produção de gemas axilares, no grau de sombreamento das touceiras e na época e sincronia do florescimento.

Em gramíneas forrageiras, os componentes do rendimento de sementes são determinados desde o desenvolvi- 
mento vegetativo até as etapas do desenvolvimento reprodutivo, destacando-se o número de inflorescências, o número de flores por inflorescência, a porcentagem e fertilidade e o peso das sementes (Carámbula, s.d.).

Entre os principais gêneros presentes nas pastagens naturais do Sul do Brasil, destaca-se o gênero Paspalum, cujas espécies apresentam baixa capacidade de produção de sementes viáveis, principalmente em virtude da diferenciação floral. Nesse caso, não ocorre o aparecimento de inflorescências e a planta vegeta durante toda a estação do ano. Em alguns casos, a planta apresenta florescimento, mas mantém (quando ocorre) baixa taxa de formação de cariopse na inflorescência e ausência de germinação das sementes por problemas de dormência (Batista \& Godoy, 1998).

Paspalum dilatatum Poir. (capim-melador) é uma das espécies mais importantes do gênero e pode ser encontrada no Sul do Brasil, no Uruguai e na Argentina. Produz forragem suculenta e comprovadamente nutritiva (Costa \& Scheffer-Basso, 2003). Souza-Chies \& Cavalli-Molina (1995) observaram variabilidade intraespecífica do potencial de produção de sementes quanto à quantidade de sementes viáveis e à germinação e salientaram que a taxa de germinação das sementes variou conforme a época da colheita e que os melhores resultados foram obtidos com sementes colhidas no início da estação de florescimento. A pobre emergência das plântulas da espécie pode ser explicada pela baixa viabilidade das sementes e pela existência de dormência das sementes recém-colhidas. Embora a dormência seja progressivamente reduzida durante o primeiro ano de armazenamento, as sementes armazenadas sofrem drástica redução na sua habilidade de germinar após um ano sob condições comerciais (Schrauf et al., 1995).

Segundo Skerman \& Riveros (1992), o capim-melador produz abundante quantidade de sementes, mas sua maturação ocorre do ápice para a base da panícula e o desgrane ocorre tão logo as cariopses fiquem maduras, o que torna difícil a colheita, induzindo à baixa viabilidade. Segundo Bennet (1976), o momento mais apropriado para a colheita é quando $60 \%$ das inflorescências apresentam cor castanho-clara.

A diversidade morfológica e citogenética do capimmelador têm sido objeto de diversos estudos. O biótipo virasoro difere dos outros encontrados no Brasil por apresentar anteras amarelas e grande número de nervuras no lema, salientes e visíveis a olho nu, pela queda de inflorescências decorrente do grande número de ramos secundários e do maior tamanho das espiguetas (Hickenbick et al., 1992), além de formar touceiras maiores.
Fenologicamente, o capim-melador possui florescimento precoce e contínuo (Costa \& Scheffer-Basso, 2003), exceto no inverno, quando as temperaturas baixas inibem a formação de afilhos reprodutivos. É um biótipo que aloca grande parte de seus fotossintatos para formação desse tipo de afilhos e que pode atingir $50 \%$ da MS somente em inflorescências, o que, somado à fração caulinar do afilho reprodutivo, ultrapassa 65\% (Baréa et al., 2007).

A importância de estudos sobre o manejo do capimmelador foi enfatizada por Carámbula (s.d.), segundo o qual, apesar de o Uruguai possuir diversos cultivares dessa espécie, cuja difusão poderia promover modificações notáveis na produção animal, a disponibilidade de sementes é praticamente nula. Segundo esse autor, esse panorama é conseqüência da falta de conhecimento em manejar a pastagem para produção de sementes, o que tem levado a fracassos injustificáveis nas diferentes etapas de multiplicação. Para as espécies nativas, o estudo fenológico é importante, pois permite compreender suas respostas funcionais ao ambiente e subsidia práticas de manejo, seja para manutenção, seja para eliminação dessas espécies (Almeida, 1995).

Este trabalho foi realizado com o objetivo de avaliar o efeito de regimes de corte durante o período anterior ao diferimento na produção de sementes do capim-melador visando incorporar novas referências à espécie e contribuir para os trabalhos de melhoramento genético.

\section{Material e Métodos}

O trabalho foi conduzido em Passo Fundo, RS, região fisiográfica do Planalto Médio, situado a $28^{\circ} 15^{\prime}$ S, $52^{\circ} 24^{\prime} \mathrm{W}$ e a 687 m de altitude, com clima fundamental úmido (Moreno, 1961). Os dados de precipitação e as temperaturas médias mensais ocorridas durante o experimento encontram-se na Figura 1. O solo do local é do tipo latossolo vermelho escuro distrófico, de textura argilosa. Após correção e adubação, a análise do solo apresentou os seguintes resultados: $\mathrm{pH}=$ 5,3; P = $13 \mathrm{mg} / \mathrm{L} ; \mathrm{K}=132 \mathrm{mg} / \mathrm{L}$ e $\mathrm{MO}=2,9 \%$.

No ensaio, avaliou-se o efeito da altura $(10 \mathrm{~cm}$ e $20 \mathrm{~cm})$ e dos intervalos de corte (30 dias e 45 dias) na produção e germinação de sementes do capim-melador, em esquema bifatorial. Os tratamentos foram alocados em blocos casualizados, com cinco repetições, sendo realizados nove e seis cortes nos intervalos de 30 e 45 dias, respectivamente, no período de setembro de 2003 a junho de 2004. O plantio foi realizado em 13 de janeiro de 2003 e cada bloco foi formado por quatro linhas de $4 \mathrm{~m}$, distantes $1 \mathrm{~m}$ entre si, cada uma com oito mudas distantes $0,50 \mathrm{~m}$ entre si. Cada linha 


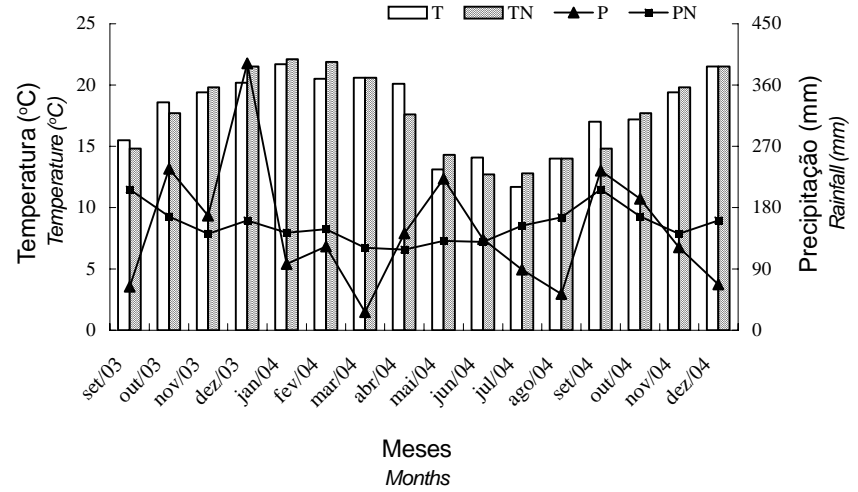

Figura 1 - Temperaturas médias $(T)$ e precipitação pluviométrica (P) mensal entre setembro/2003 e dezembro/2004 e as normais (TN, PN) (30 anos). Passo Fundo, RS. Fonte: www.cnpt.embrapa.br.

Figure 1 - Monthly mean temperatures $(T)$ and rainfall $(P)$ between September/2003 and December/2004 and the normal means (TN, PN) (30 years). Passo Fundo, RS. Source: www.cnpt.embrapa.br.

representou uma parcela e, nessas linhas, as seis plantas centrais foram consideradas área útil. Em setembro de 2003, foi feito um corte de uniformização a $15 \mathrm{~cm}$ da base das plantas, com posterior aplicação de 20 kg de N/ha. Um mês após este procedimento, foi iniciada a imposição dos tratamentos de desfolhação utilizando-se tesouras de jardinagem para a realização dos cortes. Foram aplicados $160 \mathrm{~kg}$ $\mathrm{N} / \mathrm{ha}$, fracionados em oito doses para o intervalo de 30 dias e em cinco doses para o intervalo de 45 dias, imediatamente após cada corte. O local foi mantido limpo, por meio de capinas manuais para retirada de espécies indesejáveis. A partir de julho de 2003, deixou-se o trevo-branco (Trifolium repens $\mathrm{L}$.) se estabelecer nas entrelinhas, de forma espontânea, o que controlou a expansão de poaia (Richardia sp.), guanxuma (Sida rhombifolia L.), picão preto (Bidens pilosa L.) e tiririca (Cyperus sp.). O diferimento ocorreu em junho de 2004, quando do último corte para avaliação da produção de forragem. A condição das plantas nessa ocasião foi avaliada por meio da medição da estatura, da circunferência das touceiras, da área basal (AB), do número de afilhos vegetativos e da área foliar. A área basal foi calculada pela fórmula: $\mathrm{AB}=$ circunferência ${ }^{2} .4 \mathrm{p}^{-1}$ (Hendrickson \& Berdahl, 2003). A partir do diferimento, foram calculadas as somas térmicas (graus-dia acumulados acima de $0^{\circ} \mathrm{C}$, considerada temperatura basal), para determinação dos eventos fenológicos. No período de agosto e dezembro de 2004, foram realizadas contagens semanais do número de panículas em duas plantas por linha.

A colheita das sementes, denominadas cariopses, ocorreu em 19/11 e 17/12/2004, ao primeiro sinal de queda natural das espiguetas, mediante o corte de todas as panículas presentes na área útil. Em dez panículas, foram examinados: o comprimento dos racemos basais; o número de racemos por panícula; e o comprimento da panícula, tomado desde o último nó do afilho até o ápice da panícula. Em seguida, procedeu-se à trilha e à limpeza manual, com passagem por um soprador de sementes para uso em condições de laboratório. As sementes foram armazenadas em sacos de papel e mantidas sobre um balcão em temperatura ambiente. Nesse material, foram tomadas amostras para avaliação do peso de 100 sementes, em balança de precisão, e da capacidade de germinação; para isso, foram separadas somente as sementes consideradas maduras (cor castanha). Após a pesagem, as sementes foram desinfetadas em uma solução de hipoclorito de sódio (solução comercial) a 1\%, enxaguadas, imersas em solução à base de nistatina (100.000 UI/mL) a $0,1 \%$ durante 5 minutos e novamente enxaguadas. Em seguida, foram colocadas sobre papel umedecido com nitrato de potássio a $1 \%$ para eventual quebra de dormência (Skerman \& Riveros, 1992), colocadas em caixas do tipo gerbox e levadas ao germinador a temperatura constante de $25^{\circ} \mathrm{C}$. A primeira contagem das sementes germinadas foi realizada no $7^{\circ}$ dia e a última, no $28^{\circ}$ dia. Foram consideradas plantas normais aquelas capazes de continuarem seu desenvolvimento para dar formação a plantas normais, com radícula e coleóptilo bem desenvolvidos. Os dados foram submetidos à análise de variância com comparação de médias pelo teste Tukey, realizando-se, para a taxa de germinação de sementes, a transformação dos dados em raiz quadrada de $\mathrm{y}+0,5$.

\section{Resultados e Discussão}

A condição estrutural das plantas à época do diferimento, definida ou medida pela distribuição e pelo arranjo das partes da planta acima do solo (Laca \& Lemaire, 2000), foi afetada pelo regime de cortes (Tabela 1 ). As plantas submetidas a menor condição de estresse (20 e $45 \mathrm{~cm}$ ) apresentaram maior circunferência e maior área basal, sugerindo melhor condição em tamanho de touceira. A estatura do dossel vegetativo foi afetada somente pela altura de corte, que foi reduzida sob cortes a $10 \mathrm{~cm}$, ao passo que o intervalo de corte afetou a área foliar, que foi menor em plantas desfolhadas a cada 30 dias.

O aumento da touceira do capim-melador ocorreu a partir da formação contínua de afilhos oriundos da coroa da planta e dos rizomas curtos (Costa \& Scheffer-Basso, 2003). A dimensão da touceira foi influenciada pelo regime de cortes, apesar de o número de afilhos não ter diferido entre as alturas de corte. Esse resultado pode ter decorrido do 
fato de que, na época dessa avaliação, a planta estava com seu crescimento praticamente paralisado, em virtude das baixas temperaturas, com grande quantidade de material morto no centro das touceiras, como constatado por Baréa et al. (2007), ao avaliarem a produção de forragem no ano anterior. No entanto, a relação entre a área foliar e o número de afilhos sugere que o peso dos afilhos, embora não mensurado, também foi influenciado pelas intensidades de corte, indicando efeito do manejo sobre esse componente e a importância de sua avaliação.

A partir do diferimento (29/06/2004) e do início do florescimento, decorreram 102 dias (Tabela 2). Durante os meses de maior concentração do florescimento (outubro e novembro), as temperaturas foram um pouco mais baixas $\left(17,2\right.$ a $\left.19,4^{\circ} \mathrm{C}\right)$ que o ideal para o florescimento da espécie, que, segundo Bennet (1976), é de $22,5^{\circ} \mathrm{C}$. No entanto, Pearson \& Shah (1981) observaram que, sob temperaturas de $21^{\circ} \mathrm{C}$ (dia) e $16^{\circ} \mathrm{C}$ (noite), o capim-melador Comum apresentou maior percentual de flores férteis.

Os períodos de colheita coincidiram com os relatados por Souza-Chies \& Cavalli-Molina (1995), para o mesmo biótipo, e por Carámbula (s.d.) para o biótipo Comum. Nas condições do Sul do Brasil, os resultados deste trabalho permitem afirmar que o capim-melador é precoce quanto ao florescimento e à formação de sementes e que, pelo seu comportamento indeterminado, permite mais que uma colheita de sementes na mesma estação. Nesse estudo, foi possível a realização de duas colheitas em um intervalo de aproximadamente 30 dias.

A dinâmica do florescimento do capim-melador, considerando o número de afilhos reprodutivos, foi afetada pelo regime de cortes, no qual os cortes intensos $(10 \mathrm{~cm})$ e menos freqüentes (45) favoreceram $(\mathrm{P}<0,05)$ a formação de panículas (Figura 2). Entre a época de maior número de panículas e a primeira colheita (Tabela 2), decorreram apenas dez dias, quando já foi observada a abscisão das espiguetas maduras, pela indicação da cor castanha e pela consistência seca das sementes. Esse curto período de tempo pode ter sido conseqüência da estiagem verificada em novembro-dezembro, cuja precipitação foi abaixo da normal para a região, aliada à elevação normal das temperaturas nessa época do ano, para a região de estudo (Figura 1). A formação de panículas iniciou em setembro, progrediu durante todo o mês de outubro e atingiu aproximadamente 23 panículas/planta no início de novembro, totalizando 138 panículas/linha.

As características fenológicas observadas neste estudo estão de acordo com o relatado por Carámbula (s.d) para o capim-melador, no Uruguai, onde a espécie inicia a emissão

Tabela 1 - Efeito da altura e do intervalo de corte na condição estrutural de Paspalum dilatatum biótipo Virasoro à época do diferimento (junho/2004)

Table 1 - Effect of cutting height and cutting interval in the structural condition of Paspalum dilatatum biotype Virasoro as affected by the deferment period (June/2004)

\begin{tabular}{|c|c|c|c|c|}
\hline \multirow[t]{2}{*}{$\begin{array}{l}\text { Característica morfológica } \\
\text { Morphological characters }\end{array}$} & \multicolumn{2}{|c|}{$\begin{array}{l}\text { Altura de corte } \\
\text { Cutting height }\end{array}$} & \multicolumn{2}{|c|}{$\begin{array}{l}\text { Intervalo de corte } \\
\text { Cutting interval }\end{array}$} \\
\hline & $10 \mathrm{~cm}$ & $20 \mathrm{~cm}$ & $\begin{array}{l}30 \text { dias } \\
30 \text { days }\end{array}$ & $\begin{array}{l}45 \text { dias } \\
45 \text { days }\end{array}$ \\
\hline Estatura do dossel vegetativo (cm) (Vegetative canopy height) & $23,8 b$ & 29,9 a & $31,4 \mathrm{~ns}$ & 35,1 \\
\hline Afilhos (no/planta) (Tillers, n./planta) & $40,1 \mathrm{~ns}$ & 41,6 & $39,1 \mathrm{~ns}$ & 44,5 \\
\hline Circunferência (cm) (Circunference) & $87,3 b$ & $98,0 \mathrm{a}$ & $67,9 b$ & 76,8 a \\
\hline
\end{tabular}

Médias seguidas de mesma letra não diferem $(P>0,05)$ pelo teste Tukey.

Means followed by the same letter do not differ $(P>0.05)$ by Tukey test.

Tabela 2 - Número de dias e de graus-dia (temperatura basal $=0^{\circ} \mathrm{C}$ ) entre o diferimento (junho/2004) e os eventos fenológicos de Paspalum dilatatum Poir. Biótipo Virasoro

Table 2 - Days-number and degree-days (threshold temperature $=0^{\circ} \mathrm{C}$ ) between the deferment (June/2004) and phenological events of Paspalum dilatatum Poir. biotye Virasoro

\begin{tabular}{lcc}
\hline $\begin{array}{l}\text { Evento fenológico } \\
\text { Phenological event }\end{array}$ & $\begin{array}{l}\text { Dias } \\
\text { Days }\end{array}$ & $\begin{array}{c}\text { Graus-dia }\left({ }^{\circ} \mathrm{C}\right) \\
\text { Degree-day }\end{array}$ \\
\hline $\begin{array}{l}\text { Início do florescimento (Flowering start) }(7 / 10 / 2004) \\
1 \underline{\text { a }} \text { colheita de sementes (1 }{ }^{\text {st }} \text { seed harvest) }(19 / 11 / 2004)\end{array}$ & 102 & $1.417,7$ \\
$2^{\underline{a}}$ colheita de sementes $\left(2^{\text {nd }}\right.$ seed harvest) $(17 / 12 / 2004)$ & 175 & $2.185,5$ \\
\hline
\end{tabular}




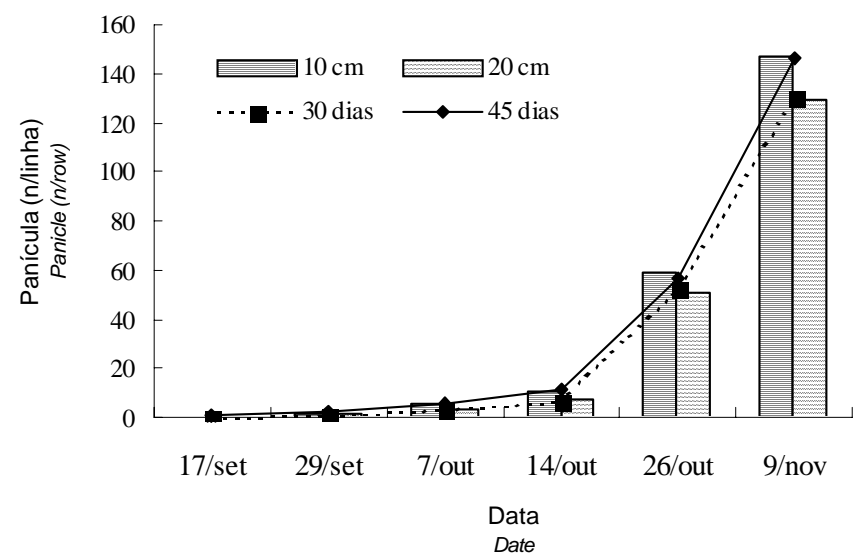

Figura 2 - Dinâmica do florescimento de Paspalum dilatatum biótipo Virasoro manejado em duas alturas e dois intervalos de corte.

Figure 2 - Flowering dynamic of Paspalum dilatatum Poir. biotye Virasoro as affected by the cutting height and cutting interval.

de panículas em setembro, produzindo de forma contínua do mês de novembro até princípios do outono. Conseqüentemente, o período de sementação é longo (Costa \& SchefferBasso, 2003) e se estende de dezembro a abril, apresentando grandes variações na quantidade e na qualidade das sementes produzidas. Essa característica, além de reduzir o valor nutritivo da forragem no campo, não é desejável, pois implica a presença de cariopses em diferentes graus de maturação na mesma panícula, dificultando a decisão da data de colheita, como descrito por Skerman \& Riveros (1992). Em ambas as colheitas, verificou-se nos lotes uma mistura de sementes verdes e castanhas, indicando que o manejo de cortes não foi capaz de promover maior sincronia no florescimento do capim-melador.

A quantidade de panículas foi, seguramente, o principal componente da produção de sementes e apresentou a mesma resposta em relação aos fatores de manejo, com maiores rendimentos sob cortes a $10 \mathrm{~cm}$ e a cada 45 dias (Tabela 3). A maior quantidade de panículas em plantas cortadas mais intensamente $(10 \mathrm{~cm})$ pode ser atribuída às melhores condições de luminosidade na base e no centro das touceiras, ocasionada pela retirada de maior perfil vegetativo. Em trabalho de Deregibus \& Trlica (1990) com o capim-melador, cortes intensos ( 2 a $3 \mathrm{~cm}$ ), desde que não freqüentes, estimularam o afilhamento na base das touceiras, em virtude de respostas morfogênicas promovidas pela melhor luminosidade. Segundo esses autores, é possível que sob boas condições de crescimento e quando a assimilação de carbono não é extremamente limitada, determinadas gramíneas aumentem o afilhamento quando desfolhadas. O manejo de corte não teve efeito nos demais componentes do rendimento, como comprimento da panícula, número e comprimento de racemos e peso de 100 sementes.

Tabela 3 - Efeito da altura e do intervalo de corte na estatura do dossel vegetativo, na produção e nos componentes da produção de sementes de Paspalum dilatatum biótipo Virasoro

Table 3 - Effect of cutting height and cutting interval in the vegetative canopy height, production, and seed production components of Paspalum dilatatum biotype Virasoro

Característica morfológica

Morphological character

Altura de corte
Cutting height

$10 \mathrm{~cm}$

$20 \mathrm{~cm}$
Intervalo de corte Cutting interval

$\begin{array}{ll}30 \text { dias } & 45 \text { dias } \\ 30 \text { days } & 45 \text { days }\end{array}$

Primeira colheita (First harvest)

Estatura do dossel (cm) (Canopy height)

Sementes (g/linha) (Seeds, g/row)

Panículas (no/linha) (Panicles, n./row)

Panículas $(\mathrm{cm}) *$ (Panicles)

Racemos (n⿳⺈/panícula) (n.panicle)

Racemos basilares (cm) (Basal racemes)

Peso de 100 sementes (g) (100 seed weight)

Germinação (\%) (Germination)

Segunda colheita (Second harvest)
Sementes (g/linha) (Seeds, g/row)

Panículas ( $\mathrm{n}$ o/linha) (Panicles, n./row)

Panículas $(\mathrm{cm}) *$ (Panicles)

Germinação (\%) (Germination)

$\begin{array}{rr}29,5 \mathrm{~b} & 32,9 \mathrm{a} \\ 47,9 \mathrm{a} & 41,0 \mathrm{~b} \\ 147,0 \mathrm{a} & 129,0 \mathrm{~b} \\ 56,5 \mathrm{~ns} & 55,8 \\ 7,0 \mathrm{~ns} & 7,2 \\ 10,2 \mathrm{~ns} & 10,0 \\ 0,17 \mathrm{~ns} & 0,16 \\ 10,3 \mathrm{~ns} & 8,7\end{array}$

$31,8 \mathrm{~ns}$

$38,7 \mathrm{~b}$

$130,0 \mathrm{~ns}$

$55,9 \mathrm{~ns}$

$7,0 \mathrm{~ns}$

10,3 a

$0,16 \mathrm{~ns}$

$12,4 \mathrm{a}$

17,2

60,9

54,2

$3,3 \mathrm{~b}$
32,9

$50,3 \mathrm{a}$

146,0

56,4

7,3

$9,9 b$

0,16

$6,6 b$

Médias seguidas de mesma letra não diferem $(P>0,05)$ pelo teste Tukey.

*Panícula + último entrenó do afilhos reprodutivo.

Means followed by the same letter do not differ $(P>0.05)$ by Tukey test.

*Panicle + last internode of reproductive tiller. 
A produção de sementes foi maior na primeira época, o que está de acordo com o observado por Carámbula (s.d), que verificou potencial de produção de sementes de 90 a 120 kg/ha para o biótipo Comum. Segundo esse autor, os melhores lotes de sementes, tanto em quantidade como em qualidade, são obtidos em colheitas precoces. Neste trabalho, estimou-se, tomando-se o tamanho dos blocos para fins de conversão de unidades de medida, produção de sementes de $40 \mathrm{~kg} / \mathrm{ha}$. Skermann \& Riveros (1992) observaram produções de 90 a 500 kg/ha para o biótipo Comum, contudo, não informaram em que condições de manejo foram obtidas essas produções.

Os resultados sugeriram que campos de capim-melador conduzidos sob pastejo, mesmo que diferidos, tem sua produção de sementes reduzida, o que também pode ser o fator da baixa taxa média de germinação das sementes (9,5\%), considerando apenas a primeira colheita, muito aquém da obtida (72,8\%) por Souza-Chies \& Cavalli-Molina (1995) para o mesmo biótipo sob condições de casa-devegetação e sem desfolhações.

Ressalta-se que, além das condições de manejo a que as plantas foram submetidas terem sido distintas, as condições de germinação foram diferentes: a temperatura do germinador foi de $25^{\circ} \mathrm{C}$ (dia e noite) e, no estudo realizado por esses autores, foi superior a $32^{\circ} \mathrm{C}$. Além disso, outros fatores abióticos podem estar relacionados a esse resultado, entre eles, as condições de colheita, secagem, umidade e tempo de armazenamento. Além disso, a mistura de sementes de diferentes graus de maturidade, em virtude da intensa pilosidade das espiguetas, tornou o trabalho de separação das cariopses muito difícil. Esse aspecto foi enfatizado por Carmona et al. (1999), que, considerando a presença de estruturas, como pêlos, aristas e cerdas em Paspalum spp., classificaram as cariopses em palhentas $(P$. pectinatum Nees e $P$. polyphilum Neees) e não-palhentas, o que implica maior ou menor facilidade de colheita e beneficiamento. Com base nesta classificação, o capimmelador é do tipo palhento, pois lema, pálea e glumas são muito pilosas. Em grama-forquilha, Maeda et al. (1997) verificaram que o calor de $40^{\circ} \mathrm{C}$ durante o armazenamento das sementes em condições permeáveis elevou de 0 para 83\% a germinação entre o primeiro e o último dia de armazenamento (150 dias), o que indica a necessidade de estudos para padronizar as condições para testes de germinação para os diferentes biótipos de $P$. dilatatum. Tischler \& Burson (1999) obtiveram melhores taxas de germinação de sementes do capim-melador “antera amarela” com tratamento em $\mathrm{H}_{2} \mathrm{SO}_{4}$ concentrado $(94,4 \%)$ em comparação ao tratamento controle $(14,8 \%)$.
Neste estudo, o manejo de cortes influenciou a germinação das sementes, sendo obtidos valores superiores para aquelas obtidas com corte intensos e freqüentes (Tabela 3 ). Pelas características avaliadas, e que poderiam explicar a princípio esses resultados, como o peso de 100 sementes, verificou-se que os resultados não estiveram relacionados às variações de germinação, indicando a necessidade de avaliações adicionais em novos estudos. Nesse sentido, a seleção das cariopses pelo seu grau de maturação é um aspecto a ser considerado. O peso de 100 cariopses cheias foi, em média, 163,15 mg, o que está de acordo com os resultados descritos por Skerman \& Riveros (1992), que obtiveram com o biótipo Comum, valores de 500.000 a 750.000 sementes $/ \mathrm{kg}$, equivalente a 200 e $133 \mathrm{mg} / 100$ cariopses, respectivamente. Há muita variação no gênero Paspalum quanto a esse aspecto. Carmona et al. (1999) citaram para P. pilosum Lam. e P. trichostomum Hack., duas espécies do cerrado brasileiro, 137 mg e 205 mg/100 cariopses, respectivamente.

Nas sementes colhidas na segunda época, tanto a produção como a qualidade de sementes foram inferiores às obtidas na primeira época, provavelmente em virtude do menor tempo entre a emissão das panículas e a maturação das sementes em relação ao ocorrido à primeira colheita. Segundo Souza-Chies \& Cavalli-Molina (1995), um aspecto importante é a diferença, em porcentagem, de sementes cheias e, conseqüentemente, a taxa de germinação entre sementes coletadas durante diferentes períodos da estação de florescimento, o que pode ser conseqüência da debulha das espiguetas maduras e da predominância de espiguetas que não formam cariopse no material obtido com a colheita das sementes tardias. No estudo realizado por esses autores, foi obtida maior quantidade de sementes cheias e maior germinação do capim-melador quando a colheita foi realizada nos primeiros meses da estação de florescimento (novembro a janeiro) em relação ao final do período (março e abril). Os autores estimaram em $80 \%$ a capacidade de enchimento de cariopses em capim-melador coletadas em plantas vegetando sob condição espontânea em áreas de campo. Reusch (1961), na África do Sul, evidenciou enchimento de no máximo 50\% no capim-melador "antera roxa”. Segundo esse autor, as diferenças entre os biótipos de capim-melador quanto à formação de cariopses, considerando basicamente o enchimento de sementes, foram diretamente relacionadas ao modo de reprodução: em biótipos sexuais, como o Virasoro e o Vacaria, houve alto percentual de sementes cheias. Neste trabalho, ao serem separadas as sementes para avaliação do peso de 100 sementes e da apacidade de germinação, observou-se que o enchimento foi praticamente total. No entanto, quando 
considerado o lote colhido, essa proporção deve ter sido menor, em razão da existência de cariopses imaturas.

Destaca-se a necessidade da continuidade de estudos com essa espécie, para agregar conhecimentos sobre práticas de manejo que maximizem a proporção de sementes cheias e maduras por ocasião da colheita e para busca de informações sobre a melhor época de colheita, incluindo tratamento testemunha (sem desfolhações). Além disso, estudos básicos para gerar informações sobre os procedimentos pós-colheita, como secagem, armazenamento, retirada ou não de glumas, entre outros, são importantes para padronização das normas para os distintos biótipos de P. dilatatum.

\section{Conclusões}

A produção de sementes do capim-melador é afetada pelo manejo de cortes anterior ao diferimento, que possibilita maiores rendimentos sob cortes a $10 \mathrm{~cm}$ de altura, que removem $75 \%$ do dossel vegetativo em maior intervalo de corte (45 dias), situação que proporciona maior número de panículas, principal componente da produção.

Os principais problemas da produção de sementes do capim-melador no Sul do Brasil são o florescimento contínuo e o curto intervalo entre o florescimento pleno e o início da abscisão das espiguetas, o que causa a mistura de cariopses com diferentes graus de maturação em mesmo lote.

\section{Literatura Citada}

ALMEIDA, S.P. Grupos fenológicos da comunidade de gramíneas perenes de um campo cerrado no Distrito Federal, Brasil. Pesquisa Agropecuária Brasileira, v.30, n.8, p.1067-1073, 1995.

BARÉA, K.; SCHEFFER-BASSO, S.M.; DALL'AGNOL, M. et al. Manejo de Paspalum dilatatum Poir. biótipo Virasoro. 1. Produção, composição química e persistência. Revista Brasileira de Zootecnia, v.36, n.4, p.992-999, 2007 (supl.)

BATISTA, L.A.R.; GODOY, R. Capacidade de produção de sementes em acessos do gênero Paspalum. Revista Brasileira de Zootecnia, v.27, n.5, p.841-847, 1998.

BENNETT, H.W. Pasto dallis, pasto bahia y pasto vasey. In: HUGHES, H.D.; HEATH, M.E.; METCALFE, D.S. (Eds) Forrajes. 6.ed. México: Compañia Editorial Continental, 1976. p.315-319.

CARÀmbUlA, M. Produccion de semillas de plantas forrageras. Editorial Hemisferio Sur: Montevideo, s.d. 518p.
CARMONA, R.; MARTINS, C.R.; FÁVERO, A.P. Características de sementes de gramíneas nativas do Cerrado. Pesquisa Agropecuária Brasileira, v.34, n.6, p.1067-1074. 1999.

COSTA, D.I.; SCHEFFER-BASSO, S.M. Caracterização morfológica e agronômica de Paspalum dilatatum Poir. biótipo Virasoro e Festuca arundinacea Schreb. 1 . Desenvolvimento morfológico. Revista Brasileira de Zootecnia, v.32, n.5, p.1054-1060, 2003.

DEREGIBUS, V.A.; TRLICA, M.J. Influence of defoliation upon tiller structure and demography in two warm-season grasses. Acta Ecologica, v.11, n.5, p.693-699, 1990.

HENDRICKSON, J.R., BERDAHL, J.D. Survival of 16 alfalfa cultivars and strains space planted into grassland. Journal of Range Management, v.56, p.260-265. 2003.

HICKENBICK, M.C.M.; FLORES, A.I.P.; CAVALLI-MOLINA, S. et al. Mode of reproduction and seed production in Paspalum dilatatum Poir. Virasoro biotype - Dilatata group (Gramineae). Revista Brasileira de Genética, v.15, n.1, p.85-102, 1992.

JOHNSTON, M.R.; OLEVARES, A.; LAURA, J. Producción y calidad de semillas en cuatro poaceas. Efecto de cortes con distintas frecuencias y en diversas etapas fenológicas. Agricultura Técnica, v.63, n.2, p.146-155, 2003.

LACA, E.A.; LEMAIRE, G. Measuring sward structure. In: 't MANNETJE, L.; JONES, R.M. (Eds.) Field and laboratory methods for grassland and animal production research. Cambridge: CABI Publishing, 2000. p.103.

MAEDA, J.A.; PEREIRA, M.F.P.; MEDINA, P.F. Conservação e superação da dormência de sementes de Paspalum notatum Flügge. Revista Brasileira de Sementes, v.19, n.2, p.164$170,1997$.

MOREnO, J.A. Clima do Rio Grande do Sul. Porto Alegre: Secretaria da Agricultura, 1961. 41p.

PEARSON, C.J.; SHAH, S.G. Effects of temperature on seed production, seed quality and growth of Paspalum dilatatum. Journal of Applied Ecology, v.18, n.3, p.897-905, 1981

REUSCH, J.D.H. The relationship between reproduction factors and seed set in Paspalum dilatatum. South African Jornal of Agricultural Science, v.4, n.4, p.513-530, 1961.

SCHRAUF, G.E.; CORNAGLIA, P.S.; DEREGIBUS, V.A. et al. Improvement in germination behaviour of Paspalum dilatatum Poir. seeds under different pre-conditioning treatments. New Zealand of Agricultural Research, v.38, p.501-509, 1995.

SKERMAN, P.J.; RIVEROS, F. Gramínea tropicales. Roma: FAO, 1992. 849p.

SOUZA-CHIES, T.T.; CAVALLI-MOLINA, S. Variability in seed production and germination in Paspalum - Dilatata Group (Gramineae). Revista Brasileira de Biologia, v.55, n.1, p.127-139, 1995.

TISCHLER, C.R.; BURSON, B.L. Seed dormancy and germination of dallisgrass, Paspalum dilatatum, stored under differing conditions. Seed Science \& Technology, v.27, p.263-271, 1999. 